\title{
REPRESENTAÇÃO DE PROFESSORES EM REDES SOCIAIS: DISCURSOS SOBRE A DOCÊNCIA E IDENTIDADE DOCENTE
}

\author{
REPRESENTATION OF TEACHERS IN SOCIAL NETWORKS: SPEECHES ABOUT TEACHING AND TEACHING \\ IDENTITY
}

\section{REPRESENTACIÓN DE PROFESSORES EN LAS REDES SOCIALES: DISCURSOS SOBRE LA DOCENCIA Y IDENTIDAD DOCENTE}

\author{
SILVA, Josiele Oliveira da ${ }^{1}$ \\ FERREIRA, Maira ${ }^{2}$
}

\section{RESUMO}

O estudo envolve discursos sobre a profissão docente na página intitulada Professores Sofredores, da rede social Facebook, visando analisar os efeitos dos discursos que ali circulam sobre a profissão e a identidade docente. A realização do trabalho se deu a partir da teorização de Stuart Hall e Marisa Vorraber Costa, na perspectiva de análise do discurso em Foucault. A análise possibilitou mostrar que em mídias são produzidos discursos e criadas representações que reforçam a questão vocacional, assim como a ideia de que o professor é um herói que deve abdicar até mesmo de sua vida pessoal em nome da educação. Alguns comentários mostram a desmotivação por parte de professores e licenciandos devido à desvalorização da docência e à violência, algumas vezes, presentes nas escolas. Os discursos sobre a profissão docente produzem efeitos no modo como os professores se veem e em sua identidade docente.

Palavras-chave: Identidade Docente. Facebook. Discurso.

\section{ABSTRACT}

The study involves speeches about the teaching profession on the page Facebook social network sufferers Teachers entitled, in order to analyze the effects of the speeches there circulating about the profession and the identity. The realization of the work took place from the theorization of Stuart Hall and Marisa Vorraber Costa, and from the perspective of discourse analysis in Foucault. The analysis made it possible to show that in medias are produced and created representations that reinforce the question of vocation, as well as the idea that the teacher is a hero who must give up even your personal life in the name of education. Some comments show the motivation on the part of teachers and licenciandos due to depreciation and violence sometimes present in schools. The speeches about the teaching profession produce effects in how teachers perceive themselves and your identity.

Keywords: Teacher Identity. Facebook. Discourse.

\section{RESUMEN}

El estudio consiste en discursos acerca de la profesión docente en la página Facebook red social que sufren que profesores titulados, con el fin de analizar los efectos de los discursos que circulan sobre la identidad y la profesión. La realización de la obra llevó a cabo desde la teorización de Stuart Hall y Marisa Vorraber costa y desde la perspectiva del análisis del discurso en Foucault. El análisis que se hizo posible mostrar que en medios de comunicación se producen y crean representaciones que refuerzan la cuestión de la vocación, así como la idea de que el maestro es un héroe que debe dar incluso su vida personal en nombre de la educación. Algunos comentarios demuestran la motivación por parte de profesores y licenciandos debido a la depreciación y la violencia a veces presente en las escuelas. Los discursos sobre la profesión de enseñanza producen efectos en cómo los profesores perciben ellos mismos y su identidad.

Palabras clave: Identidad de maestro. Facebook. Discurso.

\footnotetext{
1 Universidade Federal do Rio Grande do Sul - UFRGS - Porto Alegre - Rio Grande do Sul - Brasil

2 Universidade Federal do Rio Grande do Sul - UFRGS - Porto Alegre - Rio Grande do Sul - Brasil
} 


\section{INTRODUÇÃO}

A identidade docente é um tema bastante discutido em diferentes campos teóricos que realizam estudos na área da educação. No campo dos Estudos Culturais, apoiados na perspectiva dos estudos foucaultianos, a identidade não é vista como algo constante e que teria uma essência, uma gênese no próprio sujeito, mas como uma construção intrinsecamente ligada aos discursos sobre as posições que este sujeito ocupa na vida social, sendo importante ressaltar que o sujeito é também produtor dessa identidade, não sendo passivo durante esse processo.

A identidade docente, entendida a partir da ideia de posição de sujeito, construída pela cultura e pelos discursos que permeiam as formas como o professor se vê é produzida, permeada e interpelada pelas representações de professores e do seu papel na educação em diferentes artefatos culturais, entre esses, estão, tanto os documentos que instituem políticas públicas de formação de professores, como as mídias que representam, caracterizam e produzem imagens do que é ser professor, com potencial papel na subjetivação e criação de sua identidade. Para Hall (1997), a identidade emerge do diálogo entre os discursos que fazem sentido em uma dada cultura, sendo possível, no que tange à profissão docente, trazer essa compreensão para a construção da identidade dos professores.

Essa construção identitária se dá pela interpelação de discursos sobre a escola e sobre a docência, mas também pelas mídias quando referem o papel social dos professores em narrativas, em filmes ou em documentários, nos quais diferentes representações do exercício da docência são produzidas. Em filmes hollywoodianos, por exemplo, é comum alunos problemáticos serem "salvos" por um professor herói que os ajuda a encontrar o caminho da dedicação, dos estudos e de um futuro promissor.

Representações como essa ocorrem também em novelas, com reconhecimento e admiração dos espectadores, pois se constitui no discurso político e assistencial da escola como salvadora dos sujeitos e de suas almas, que necessita, para cumprir esse papel, contar com a colaboração de professores dedicados, abnegados e afetuosos, reforçando a compreensão da sociedade sobre quais seriam as qualidades de um "bom" professor. Para Borges (2012), o sucesso desses filmes, está sempre associado a afetividade e a empatia do professor em relação aos seus alunos, bem como ao bom desempenho, inicialmente dos professores e, como consequência, dos alunos.

Representações da docência e da profissão docente também podem ser reconhecidas em outras mídias, como em redes sociais, em canais do YouTube ou em outros espaços de comunicação online. Nesses ambientes virtuais, as representações acerca dos docentes e do seu exercício profissional criam verdades e marcam posições de sujeito, produzindo efeitos sobre os processos de subjetivação e identidade dos professores.

Neste trabalho, analisamos três publicações da página "Professores Sofredores", da rede social Facebook, no período de abril a junho de 2016. A análise de postagens, imagens e textos visou compreender o modo de como os discursos que circulam nesse espaço produzem efeitos nos 
processos de subjetivação e de identidade docente, tendo como pressupostos teórico-metodológicos os conceitos de cultura (HALL, 1997) e discurso (FOUCAULT, 2014; 2015).

\title{
A PROFISSÃO DOCENTE NAS TRAMAS DA CULTURA E DO DISCURSO
}

As reflexões sobre a identidade docente vêm acompanhadas de discussões sobre a autonomia e os processos de profissionalização e proletarização da profissão (ENGUITA, 1991; GARCIA, 2015). Nesse sentido, esse assunto se mostra uma questão importante, considerando que os muitos discursos sobre a profissão de professor/a, seja nos cursos de formação, nas mídias ou em outras esferas da sociedade, produzem efeitos no modo como esses professores se veem e veem a sua profissão. Pode-se tentar compreender os processos instituidores de identidades em uma sociedade, a partir do entendimento de que

\begin{abstract}
Os seres humanos são seres interpretativos, instituidores de sentido. A ação social é significativa tanto para aqueles que a praticam quanto para os que a observam: não em si mesma mas em razão dos muitos e variados sistemas de significado que os seres utilizam para definir o que significam as coisas e para codificar, organizar e regular sua conduta uns em relação aos outros. Estes sistemas ou códigos de significado dão sentido às nossas ações. Eles nos permitem interpretar significativamente as ações alheias. Tomados em seu conjunto, eles constituem nossas "culturas". Contribuem para assegurar que toda ação social é cultural, que todas as práticas sociais expressam ou comunicam um significado e, neste sentido, são práticas de significação. (HALL, 1997, p. 16).
\end{abstract}

Considerando a cultura nessa perspectiva, entende-se a identidade a partir da ideia de posição de sujeito, construída, pela e na cultura, em discursos e processos de subjetivação que permeiam as formas como este se vê como um ator social. Para Hall (1997), "a identidade emerge, não de um centro interior, de um eu verdadeiro e único, mas do diálogo entre os conceitos e definições que são representados para nós pelos discursos de uma cultura [...]" (p.26). Assim, podemos reconhecer a cultura como constituindo e sendo constituída por sujeitos e práticas sociais que, por sua vez, são interpelados, mais por alguns discursos do que por outros, subjetivando-se a modos de ver e de viver neste mundo. Na perspectiva pós-estruturalista, entende-se que "quando se tenta rearticular as relações entre os sujeitos e as práticas discursivas, a questão da identidade emerge, ficando evidente que é por meio das interações comunicativas que elas são construídas" (HALL, 1976, apud ROCHA, 2008). Ainda, de acordo com Hall, os processos de subjetivação ocorrem a partir da linguagem, mediante sistemas de significação, ou seja,

[...] a cultura não é nada mais do que a soma de diferentes sistemas de classificação e diferentes formações discursivas aos quais a língua recorre a fim de dar significado às coisas. $\mathrm{O}$ próprio termo "discursivo" refere-se a uma série de afirmações, em qualquer domínio, que fornece uma linguagem para se poder falar sobre um assunto e uma forma de produzir um tipo particular de conhecimento. (HALL, 1997, p. 29). 
Assim, as práticas sociais têm uma dimensão cultural e estas dependem e têm relação com os discursos, que, por sua vez, instituem significados e práticas. A partir dessas concepções, podemos entender o discurso como,

\begin{abstract}
um conjunto de enunciados, na medida em que se apoiem na mesma formação discursiva; ele não forma uma unidade retórica ou formal, indefinidamente repetível e cujo aparecimento ou utilização poderíamos assinalar (e explicar, se for o caso) na história; é constituído de um número limitado de enunciados para os quais podemos definir um conjunto de condições de existência. (FOUCAULT, 2014, p. 143).
\end{abstract}

Essa compreensão possibilita ver a escola como um espaço em que circulam diferentes discursos, aos quais os sujeitos também são subjetivados. Para Costa (2000), "as sociedades e culturas em que vivemos são dirigidas por poderosas ordens discursivas que regem o que deve ser dito e o que deve ser calado e os próprios sujeitos não estão isentos desses efeitos" (p.3). Entende-se, a partir disso, que a linguagem não apenas fala sobre as coisas, mas as cria, assim como cria identidades e modos de ser dos sujeitos. Ao analisar práticas educativas e a constituição e identidade do pedagogo, é possível trazer a seguinte consideração:

\begin{abstract}
Ao analisarmos as antigas práticas de condução dos aprendizes, a gênese da escola e a constituição do pedagogo (um homem, quase sempre um religioso), vemos que a pedagogia já se constituiu em outros tempos e espaços por outras práticas sociais, em que tanto o pedagogo quanto a pedagogia se diferenciavam do padrão que temos hoje [...] Um e outro não possuem uma essência; ambos se constituem nas práticas sociais. Isso não significa negar a materialidade, mas aceitar que a realidade é construída sobre a materialidade dos corpos e práticas. (FABRIS, 2010, p. 233).
\end{abstract}

A partir dessa concepção de posição de sujeito e de processos de subjetivação, buscou-se compreender como são produzidas as representações sobre a docência em uma dada época e de que modo essas representações produzem identidades docentes na página ora analisada. Entende-se que as identidades são constituídas em meio a uma rede de discursos, presentes em documentos oficiais, em currículos de cursos de formação de professores e nas mídias, entre outras materialidades.

\title{
AS MÍDIAS E A CONSTITUIÇÃO DE MARCAS DA PROFISSÃO E IDENTIDADES DOCENTES
}

Olhar a questão da identidade docente em uma perspectiva cultural implica reconhecer que, tanto os discursos que dão significado aos documentos oficiais, quanto os que circulam em outros espaços (como as mídias) representam os sujeitos escolares, os alunos e, principalmente, os professores, dando significado às suas práticas. Nesse sentido, é possível

tratar da identidade docente é estar atento para a política de representação que institui os discursos veiculados por grupos e indivíduos que disputam o espaço acadêmico ou que estão na gestão do Estado. É considerar também os efeitos práticos e as políticas de verdade que discursos veiculados pela mídia impressa, televisiva e cinematográfica estão ajudando a configurar. A identidade docente é negociada entre essas múltiplas representações entre as 
quais, e de modo relevante, as políticas de identidade estabelecidas pelo discurso educacional oficial. (GARCIA, HYPÓLITO \& VIEIRA, 2005, p. 47).

Em direção semelhante, para Rosa, "as possibilidades de influências recíprocas entre professores em serviço e licenciandos contribuem para fazer circular discursos próprios da formação docente" (2010, p. 416), sendo esses discursos formadores de redes discursivas, nas quais os professores se veem representados. Consideramos os discursos como produtores de identidades/modos de ser professor/a e que produzem efeitos no trabalho docente. Costa (2010) aponta que algumas representações de professores nas mídias, por vezes, confrontam discursos tradicionais e contemporâneos sobre o papel e o trabalho dos professores, com efeitos na constituição da própria profissão docente.

Nesse sentido, são produzidos modos de ser e de se ver professor/a, identificado como alguém que possa dominar um conjunto de competências relativas à sua área de atuação. Para Garcia (2010), a questão da identidade docente está associada a um "conjunto de características, experiências e posições de sujeito atribuídas (e autoatribuídas) por diferentes discursos e agentes sociais que nomeiam os docentes no exercício de suas funções, em instituições educacionais mais ou menos complexas e burocráticas" (p.1). Entende-se que a identidade compreendida no âmbito da cultura, como modo de representação que constitui o objeto sobre o qual fala, não deve ser vista como algo fixo ou essencial aos sujeitos, não pode ser tomada como sendo constante e permanente em um professor que tem uma gênese no próprio sujeito. Deve ser considerada como uma construção social que está intrinsecamente ligada aos discursos sobre as posições que este sujeito ocupa e as representações sobre seu papel social. Dessa forma, Garcia (2010) argumenta que

\begin{abstract}
A identidade docente é, ao mesmo tempo, um processo de identificação e diferenciação, não fixo e provisório, que resulta de negociações de ordem simbólica que os professores realizam em meio a um conjunto de variáveis como suas biografias, as relações e condições de trabalho, a história e a cultura que caracteriza a docência enquanto atividade profissional, e representações colocadas em circulação por discursos que disputam os modos de ser e agir dos docentes no exercício do ensino e do trabalho docente. (GARCIA, 2010, p. 1).
\end{abstract}

Fazendo uma analogia com a teorização de Costa (2009) sobre a representação da infância ao longo da história, a ideia de identidade docente também pode ser tomada como fazendo parte das "construções sociais, todas elas produzidas pelas culturas em que estão inscritas e marcadas por profundas transformações sociais, políticas, econômicas, e culturais que assistimos a partir do século XX" (p. 67). Nóvoa (1995) se aproxima dessa ideia de identidade quando aponta que essa,

[...] não é um dado adquirido não é uma propriedade, não é um produto. A identidade é um lugar de lutas e de conflitos, é um espaço de construção de maneiras de ser e de estar na profissão. Por isso, é mais adequado falar em processo identitário, realçando a mescla dinâmica que caracteriza a maneira como cada um se sente e se diz professor. E vice-versa. (NÓVOA, 1995, p.34). 
No caso do estudo realizado, consideramos as identidades docentes constituídas discursivamente em uma dada época, sendo produzidas em diferentes espaços, como os currículos de cursos de formação inicial, os documentos oficiais, e/ou as mídias, entre outros artefatos da cultura. Nesse sentido, a mídia,

\begin{abstract}
ao mesmo tempo que é um lugar de onde várias instituições e sujeitos falam como veículo de divulgação e circulação dos discursos considerados "verdadeiros" em nossa sociedade, também se impõe como criadora de um discurso próprio. Porém, pode- se dizer que, nela, talvez mais do que em outros campos, a marca da heterogeneidade, além de ser bastante acentuada é quase definidora da formação discursiva em que se insere. Poderíamos dizer que hoje praticamente todos os discursos sofrem uma mediação ou um reprocessamento através dos meios de comunicação. (FISCHER, 2001, p. 212).
\end{abstract}

Os diferentes discursos constitutivos da identidade docente, por vezes, se reforçam ou se complementam como, por exemplo, os discursos pedagógico e político que legitimam os documentos oficiais, orientando a formação dos professores e a realização de suas práticas na escola. As Diretrizes Curriculares Nacionais para a Formação de Professores - DCNFP (BRASIL, 2015), como a maioria dos documentos oficiais, têm nos discursos da inovação e da prática elementos que enfatizam requisitos para uma "boa" formação docente. Nesse sentido, as políticas educacionais curriculares poderiam ser compreendidas como

\begin{abstract}
um dispositivo de governamentalidade, instituindo significados acerca da formação humana e racionalidades que fabricam formas de subjetividade e relações sociais. As políticas curriculares e as reformas são dispositivos de regulação social que vinculam objetivos administrativos do Estado à liberdade dos sujeitos, e suas implicações fundamentais estão no modo como os sujeitos são levados a construírem suas experiências subjetivas e a posicionarem-se nas relações sociais. (POPKEWITZ, 1997 apud GARCIA, FONSECA \& LEITE; 2013, p. 237).
\end{abstract}

A noção de dispositivo de governamentalidade é, para Foucault (2015), uma forma de gestão global dos sujeitos de uma determinada categoria (rede discursiva), considerando-a como uma biopolítica, por entender ser mais do que uma gestão dos sujeitos, um controle de estratégias que são sempre atravessadas por relações de saber-poder, produzindo efeitos na produção dos sujeitos sociais. No caso da educação brasileira e da formação de professores pode-se perceber que as DCNFP (BRASIL, 2015) vão ao encontro das DCNEB (BRASIL, 2013), quando afirmam que a formação inicial e continuada do professor deve ser assumida "como compromisso integrante do projeto social, político e ético, local e nacional, que contribui para a consolidação de uma nação soberana, democrática, justa, inclusiva e capaz de promover a emancipação dos indivíduos e grupos sociais" (p. 58). As DCNEB apontam, ainda, que as demandas da escola dos dias atuais requerem que os professores deixem "de ser transmissores de conhecimentos para serem mediadores, facilitadores da aquisição de conhecimentos; devem estimular a realização de pesquisas, a produção de conhecimentos e o trabalho em grupo" (BRASIL, 2013, p. 218).

Nota-se, neste momento, mais um reforço para a responsabilização do professor com relação à mudanças para a melhoria da educação. Segundo Garcia, Fonseca \& Leite (2013), os textos das 
políticas públicas definem os lugares que devem ser ocupados pelos sujeitos da escola, assim como configuram as relações de poder entre estes. Como já dito, além das representações sobre a profissão docente instituídas em documentos oficiais, também os discursos que circulam em outros meios, como no cinema, por vezes, caracterizam o "bom" professor como o "salvador" de seus alunos, especialmente em escolas que carregam o estigma de fracasso. Nessa perspectiva, é possível compreender que

a representação e os significados que circulam nos filmes sobre os docentes apontam os mitos presentes culturalmente em relação a esta atividade, como a necessidade de abdicar da vida pessoal em função da profissional, e a relação entre o professor-aluno com ênfase nos aspectos emocionais. (BORGES, 2012, p. 306).

Em filmes hollywoodianos isso está bastante presente, quando o enredo gira em torno de um modelo de "bom professor" que "salva" os alunos e, consequentemente, a escola, que se encontrava em situação de fracasso. Essa marca salvacionista da profissão docente pode ser notada, por exemplo, no filme intitulado "Escritores da Liberdade", no qual a professora inicia a carreira docente numa escola periférica, em uma turma de alunos que tem a marca do "fracasso". Para educá-los, a professora abre mão da sua família e dedica todo o seu tempo e energia para "livrar" seus alunos do fracasso.

Assim como no cinema, também as redes sociais são espaços onde tais discursos são produzidos, principalmente porque nelas a interação com outras mídias ocorre de forma mais significativa. Na rede social Facebook, a página intitulada "Professores Sofredores" pode ser um exemplo de como os discursos sobre o "ser" professor representam o trabalho e a profissão docente associados à vocação, à salvação de almas, ao mesmo tempo que tecem comentários acerca da desvalorização da profissão.

Nas imagens, narrativas e comentários postados, a escola é representada como instituição que, embora "fracassada", se apresenta como única possibilidade de resgatar os alunos "perdidos". Essa concepção do papel da escola e do trabalho dos professores traz marcas da história de criação das escolas e da educação escolar. Segundo Marcelo (2009), as escolas foram criadas com o intuito de transformar as mentes dos alunos em mentes educadas, tendo sido essa a exigência aos professores: o ensino como princípio para educar. Nessa direção, é possível pensar que "em todas as nações existe um consenso emergente de que os professores influem de maneira significativa na aprendizagem dos alunos e na eficácia da escola" (COCHRAN-SMITH \& FRIES, 2005 apud MARCELO, 2009, p. 9). Com relação ao papel dos professores na educação escolar, as mídias atuam de forma recorrente na construção de modos de ser de sujeitos imersos em uma dada cultura que, no caso da docência, implica dar visibilidade ao trabalho docente. Ao discutir o papel produtivo das mídias, é possível destacar que 
uma mediação ou um reprocessamento através dos meios de comunicação. (FISCHER, 2001, p. 212).

A análise das postagens da página se refere às imagens e aos comentários envolvendo o exercício da docência, cujas enunciações remetem à marcas históricas da profissão docente. As postagens analisadas foram publicadas no período de abril a junho de 2016, sendo selecionadas três publicações e dez principais comentários de cada uma delas. Ao olhar para os comentários, levamos em consideração que os receptores das postagens também são colocados em evidência, uma vez que constroem sentidos ao que é produzido.

Na pesquisa realizada, o objetivo foi analisar, a partir da noção de cultura e discurso, as representações sobre a profissão docente nessa rede social, bem como seus efeitos nos processos de subjetivação e construção de identidades docentes, tanto para os que estão em formação inicial, quanto para os já licenciados. A construção e análise de dados foram realizadas na perspectiva da Análise do Discurso, baseada em Michel Foucault, considerando os discursos como produtores de significado para os objetos sobre os quais falam. Para Foucault, as palavras e sentidos se estabelecem no discurso, ou seja, ao analisar discursos considera-se os enunciados como elementos que, interligados ou associados, colocam o discurso em funcionamento, estando esses sempre atravessados por relações de poder.

A análise do campo discursivo é orientada de forma inteiramente diferente; trata-se de compreender o enunciado na estreiteza e singularidade de sua situação; de fixar seus limites da forma mais justa, de estabelecer suas correlações com os outros enunciados a que pode estar ligado [...] (FOUCAULT, 2015, p. 34).

Assim, procuramos mostrar o modo como as postagens na referida página do Facebook operam discursos que dão visibilidade às ações associadas à docência, como modo de legitimação da profissão docente.

\section{PROFESSORES SOFREDORES EM DISCURSOS E PRÁTICAS}

Como já dito, a representação da docência nas mídias, mais especificamente em uma página do Facebook, foi o foco desta pesquisa. Considera-se que proceder uma análise cultural envolvendo as mídias sociais, implica olhar discursos que instituem representações de sujeitos e de suas práticas. No caso da página "Professores Sofredores", desde sua criação em abril de 2012, já recebeu, até o momento da escrita deste trabalho, 346.598 curtidas. Como qualquer comunicação midiática, a página tem um modo de endereçamento, sendo importante compreender como se dá o seu funcionamento.

Os modos de endereçamento são as maneiras como as relações entre endereçador e endereçado são construídas em um texto. Para se comunicar, o produtor de um texto precisa fazer algumas suposições a respeito de uma audiência pretendida: reflexos dessas suposições podem ser encontrados no texto. Assim, pensar quem é a audiência não só a define, mas, 
também, o próprio produto, já que isto interfere nas escolhas envolvidas no seu processo de construção. (CHANDLER, 2012 apud ROCHA et. al., 2010)

$\mathrm{Na}$ apresentação da página, há um chamado para trocas de experiências, desabafos e reclamações, fazendo referência às questões que remetem para a desvalorização dos professores, como as dificuldades em relação aos salários e ao comportamento dos alunos. Questões essas que, de acordo com Pereira, estão associadas à proletarização dos professores, considerando ser este um processo diretamente relacionado ao "aviltamento salarial e participação cada vez menor na execução do seu próprio trabalho" (2006, p. 25). A descrição da página dá uma ideia de seu endereçamento.

Se você é professor, da rede pública ou particular, de escolas de idiomas ou profissionalizantes e professor universitário, esta é a comunidade para você desabafar, trocar experiências e reclamar do SALÁRIO e do crescente mau comportamento dos alunos. A classe docente precisa se unir e ser valorizada (logo)!

Compondo a página de apresentação, há uma foto de perfil com a frase "Educação não é mercadoria" e uma foto de capa, com a imagem de várias mãos segurando o planeta terra. Ambas foram publicadas no dia 13/10/2013 e, embora a análise dessa pesquisa tenha sido realizada entre abril e junho de 2016, as fotos de capa e perfil, assim como os comentários sobre as mesmas também foram analisadas, pois estas ainda faziam parte da apresentação da página no período de análise desta pesquisa. Algumas representações sobre a profissão docente podem ser percebidas nos comentários sobre as fotos de perfil/capa da página, como mostram os excertos que seguem:

ser Professor é cooperar com o Progresso. É uma Vocação antes de ser uma profissão. Coragem Força Esperança! (05/08/2015)

Se você escolheu ser professor. Seja professor de garra. Tem que ter muita vontade. Gostar de verdade do que faz [...] para conseguir ensinar direito. (11/02/2015).

Nos comentários acerca do tema e dos assuntos tratados na página, é bastante enfatizada a relação entre profissão docente e vocação, sendo necessário ao professor ter garra, determinação, força de vontade e esforço. Nesse sentido, representações do trabalho docente associados à vocação e/ou à força de vontade, torna o processo de proletarização docente mais rápido e com resultados que dificultam a valorização da profissão, dificultando diminuindo também

a participação efetiva dos professores na organização da categoria profissional e na luta pelas reivindicações salariais. Além de dificultar a ação mais efetiva entre os professores, cria a resistência da própria sociedade em relação ao movimento dos mesmos, pois the cobra uma postura vocacional, de doação. (KREUTZ, 1991 apud PEREIRA, 2006, p. 23). 
De acordo com Costa (2010), "as novas tecnologias, com todo o aparato discursivo que comportam, são "uma espécie de produtoras da subjetividade. De novos jeitos de ser sujeito. Novas formas de viver, novas formas de ser pessoa humana" (p. 147). Nesse sentido, nas redes sociais circulam discursos que subjetivam os sujeitos e reforçam identidades, algumas históricas como, por exemplo, a identidade de professor vocacionado ou de professor (exclusivamente) dedicado ao seu trabalho. Essa representação é reiterada na postagem que contém imagem e texto de um professor da Índia que atravessava um rio para dar aulas.

Fig. 1

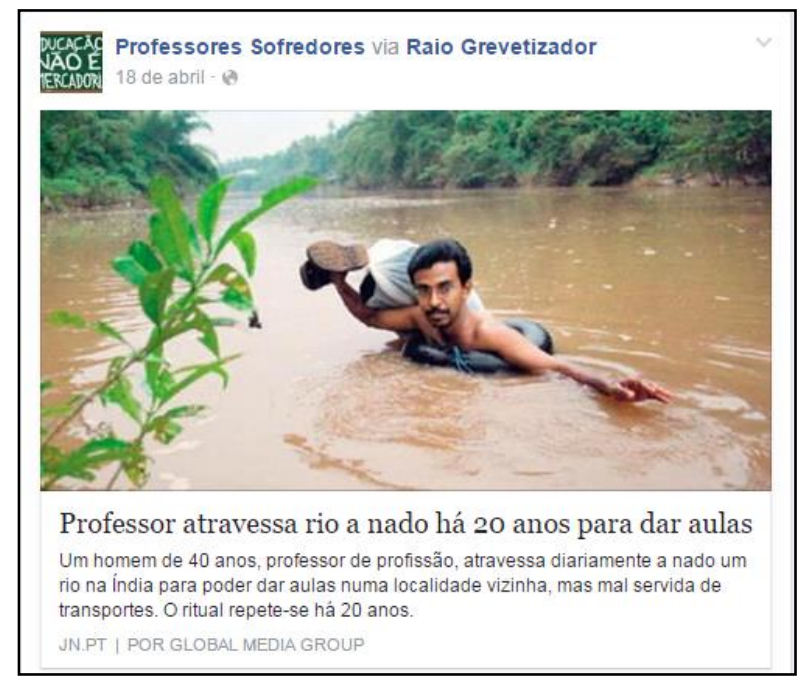

Sobre a postagem foram feitos diversos comentários, sendo alguns desses, os que seguem:

Um profissional que se respeita e que ama o que faz, faz a diferença (parabéns).

Não é somente por dinheiro, tem que ter amor, amo ser professor!

Guerreiro, esse sim quer o bem do país.

Esse é um herói.

Os principais comentários na postagem reforçam a ideia de que um bom professor é um guerreiro, um herói, cujo exercício da profissão exige dedicação e sofrimento. Nesses, e em outros comentários acerca do tema e dos assuntos tratados na página, é enfatizada a relação: profissão docente com vocação, força de vontade, esforço e dedicação extremada. Pode se pensar que o enunciado que refere a vocação como inerente à profissão docente compõe, junto com outros enunciados dos discursos pedagógico, político e social, um panorama da educação escolar, no qual os próprios professores tentam se encaixar, justificando, em função disso, que, apesar de todas as dificuldades, se esforçam para conseguir levar em frente seu trabalho de educar crianças, jovens e adultos, o que também contribui para a constituição da sua identidade docente. Rocha (2010) explica que 
a construção das representações e das identidades é feita narrativamente. O sentido que conferimos ao mundo e à nossa posição nele, se configura quando organizamos nossas experiências de maneira a conferir-lhes causalidade e ordenamento (ROCHA et. al., 2010, p. 89).

A ideia de dedicação exclusiva ao ensino, pondo em risco a própria vida, em nome do ofício de ensinar, de orientar e cuidar dos alunos, é um modo frequente de representar o "bom" professor nas mídias, sendo comum, por exemplo, em filmes e novelas/seriados de TV. De acordo com Borges (2012), "a representação nos filmes sobre a docência, aponta os mitos já presentes culturalmente em relação a esta atividade, como a necessidade de abdicar da vida pessoal em função da profissional" (p. 306). Além disso, outro aspecto da profissão docente apontada nas postagens refere às relações de tensão que se criam nas relações entre professores e alunos, pois certamente, relações que envolvem situações permeadas por tensões e violência na escola contribuem para o mal-estar docente e a evasão profissional dos professores, ainda em início de carreira.

A violência escolar é um aspecto que tem crescido bastante nos últimos anos se tornando um problema social no Brasil e em outros países. De acordo com Lopes \& Gasparin (2003), "a presença mais intensa da violência, no cotidiano da escola, tem aumentado a complexidade da relação professor-aluno e tornado mais agudos os conflitos próprios da relação" (p. 295). Notícias nas mídias de TV e jornais sobre atos de violência física por parte de alunos contra os professores, normalmente, trazem consigo chamadas sensacionalistas, reforçando os discursos que colocam a escola como sendo um lugar perigoso e de difícil convivência. Sobre a violência na escola, há a publicação na página "Professores Sofredores" contendo uma notícia de 31/05/2016 sobre alunos que atearam fogo na cabeça de uma professora em uma escola no estado de São Paulo.

Fig. 2

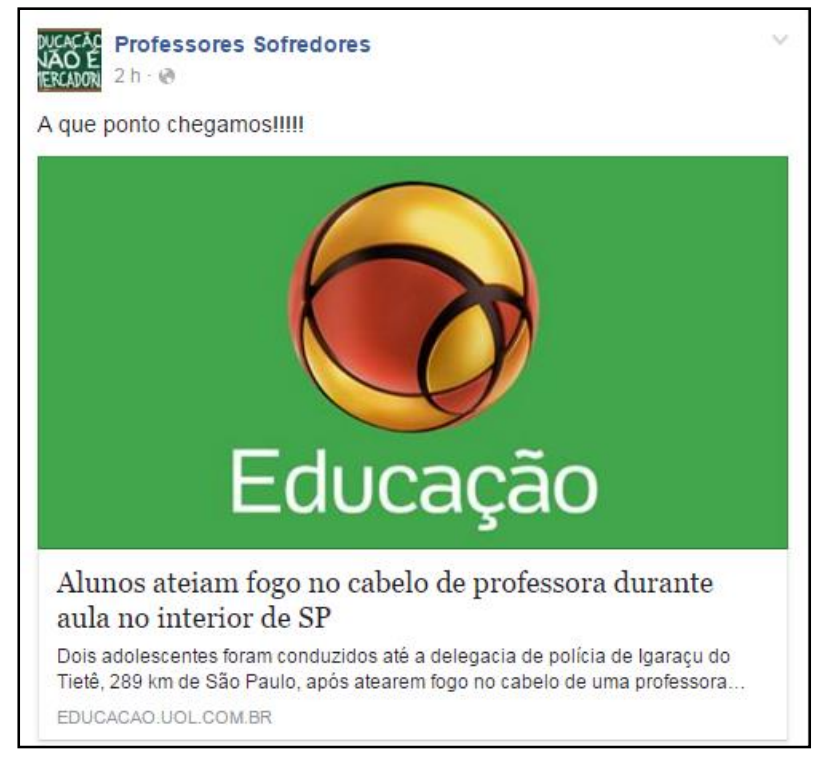


Com relação a essas relações conflituosas entre professores e alunos, podemos compreendêlas também como um efeito das representações acerca do professor e de seu papel social na escola, uma vez que as mudanças ao longo do tempo produziram, também, mudanças na concepção acerca da profissão docente. Dessa maneira, Lopes \& Gasparin (2003) apontam que:

\begin{abstract}
Podemos dizer que, durante muito tempo, a atitude dos professores diante de seus alunos era presumível. Suas atribuições, o campo próprio de sua atuação, enfim, suas tarefas, eram socialmente muito mais definidas. No entanto, na atualidade, parece ser fato que há toda uma complexificação em torno do consenso social sobre educação e um aumento das exigências em relação ao professor. (LOPES \& GASPARIN, 2003, p. 298).
\end{abstract}

O fato é que isso tudo afeta os professores, produzindo efeitos de ordem física e psicológica dos mesmos, pois segundo Sanches (2015), "agressões verbais e insultos aos professores, mais frequentes e difíceis de quantificar que as agressões físicas, têm um importante efeito sobre a constituição do mal-estar docente." ( p. 31). Podemos perceber a constituição desse mal-estar docente nos comentários na publicação citada anteriormente (Fig.2).

Isso mostra a deterioração do sistema educacional falido desse país.

É também por esse tipo de coisa que não vejo a hora de me aposentar.

Por essas e outras... tô saindo dessa área.

É por isso e muito mais que ninguém quer mais ir para o magistério...

Segundo Lopes \& Gasparin (2003), é evidente que não são somente os casos de violência a origem do mal-estar docente, mas também o desgaste e os conflitos que a relação professor-aluno desencadeia nos professores. As falas acima mostram que a violência e as relações conflituosas construídas entre professores e alunos, como já ditos, podem ser determinantes para a saída de profissionais na área da educação. Nesse sentido, é necessário ressaltar que a evasão docente é um aspecto importante a ser analisado e que a falta de perspectivas da profissão contribui para o pouco interesse com consequente diminuição de graduandos em cursos de licenciatura e de pedagogia. $\mathrm{Na}$ publicação da página analisada, no dia $1^{\circ}$ de maio de 2016 , há uma postagem sobre notícia publicada em fev/2015, referindo ao abandono de profissionais docentes à sala de aula. 
Fig. 3

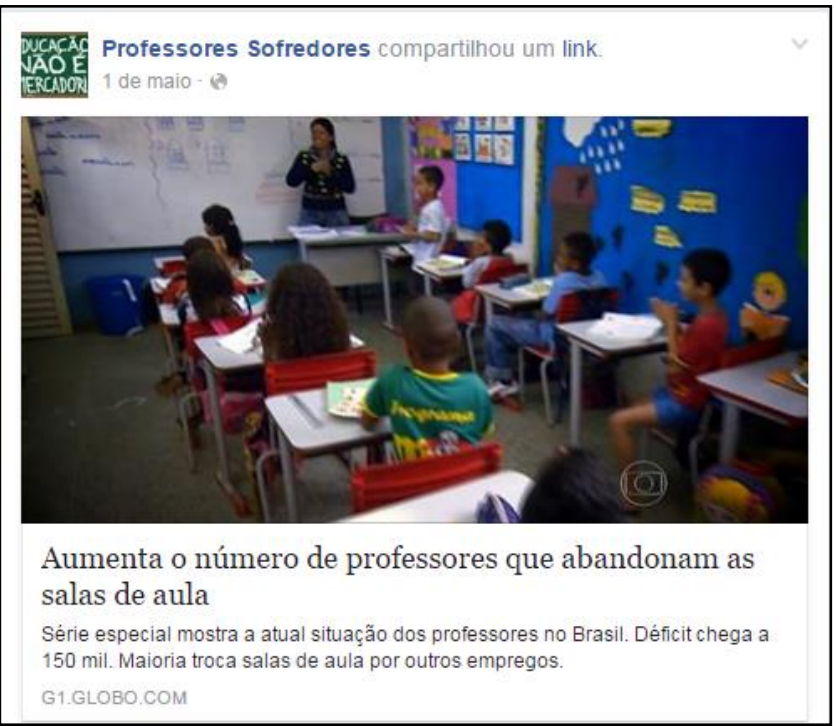

Entende-se a evasão da profissão docente como um dos efeitos da desvalorização da carreira profissional dos professores e do ensino, conforme pode ser observado nos comentários postados por futuros professores.

Faço estágio em uma escola e vendo a situação atual na sala de aula percebi que não sou capaz de atuar como professora. Já me dedico nos estudos para seguir em outra área.

Eu faço faculdade, em licenciatura, e quase todos os dias vejo notícias que me desanimam de ser professor.

Os comentários mostram a desmotivação dos licenciandos em seus cursos de formação inicial, causando impacto em outros professores em formação.

As postagens analisadas, publicações e comentários mostram, por um lado, a valorização do exercício da docência em relação ao empenho, à vocação e ao sacrifício dos professores para a realização de um trabalho importante e necessário. Por outro lado, indo em outra direção, destacam os efeitos da desvalorização da profissão docente pela evasão dos professores das salas de aula. Em meio a esses diferentes discursos e representações, os professores se constituem como sujeitos que enfrentam desafios diários e superam dificuldades, ou como sujeitos que avaliam perspectivas com relação à profissão e "desistem" da carreira que escolheram. Em diferentes direções, os professores, especialmente os que estão em formação inicial, vão construindo sua identidade docente, considerando os diferentes discursos, sejam eles midiáticos, pedagógicos, políticos, ou de outra natureza, muitas vezes associados às histórias pessoais de cada um. Nesse sentido, com relação à constituição da identidade dos professores, compreende-se, segundo Rocha (2011), que cada sujeito: 
é produzido socialmente, vive numa formação social particular e é constituído por uma complexa história cultural, que é tanto social quanto textual. Sua subjetividade resulta tanto da experiência social real quanto da experiência mediada ou textual e exerce uma influência significativa na construção dos sentidos. A produção de sentido a partir de um texto tem similaridades com o processo da construção da subjetividade dentro da sociedade. (ROCHA, 2011, p. 13).

A partir das análises realizadas, destacamos que as mídias, mais especificamente as redes sociais, são artefatos culturais que, ao representar os professores e a profissão docente, produzem suas identidades. As publicações da página do Facebook "Professores Sofredores", assim como em filmes e em outras mídias, operam, a partir de enunciados, discursos e representações sobre a docência e a profissão docente, em processos de subjetivação que têm efeitos na identidade dos professores. As análises realizadas na perspectiva da cultura como constitutiva de significados sociais, se mostraram adequadas para dar visibilidade aos discursos que operam na produção e no modo como os professores se percebem e veem a sua profissão.

\section{CONSIDERAÇÕES FINAIS}

A partir da análise cultural proposta, considerando a concepção de discurso em Michel Foucault, discutimos a constituição de identidades docentes e o quanto algumas marcas históricas ainda permanecem na atualidade. No que tange ao modo como os professores veem o seu trabalho e a profissão docente, a análise das publicações da página do Facebook "Professores Sofredores", indica haver um endereçamento aos professores da Educação Básica, formados ou em formação, para que manifestem, nas publicações e nos comentários, modos de representar a docência e a profissão docente.

Observou-se que os discursos sobre a profissão docente e sobre características e modos de ser de um "bom professor" circulam nas imagens e textos postados, produzindo efeitos na identidade docente dos professores, no modo como o professor (ou futuro professor) se vê e vê a sua profissão. Nas redes sociais, assim como em outros artefatos culturais, são produzidas representações e verdades sobre a escola, os professores e a docência, que precisam ser discutidas e problematizadas.

\section{REFERÊNCIAS}

1. BORGES, Fabrícia Teixeira. A professora que vemos nos filmes: construção identitária e significados da docência. Cadernos CEDES, Campinas, v. 32, n. 88, dez. 2012 .

2. BRASIL. CNE/CEB Ministério da educação, Secretaria de Educação Básica. Resolução n 4, de 13 de julho de 2010 define Diretrizes Curriculares Nacionais da Educação Básica. Brasília jun. de 2013. Disponível em: < http://www.mec.gov.br/> 
3. BRASIL.CNE/CEB Ministério da educação, Secretária de Educação Básica. Resolução $\mathbf{n}^{\circ} \mathbf{2}$, de $\mathbf{1}^{\circ}$ de Julho de 2015 define Diretrizes Curriculares Nacionais para a Formação de Professores. Brasília, p. 1- 15 de jun. de 2015. Disponível em: < http://www.mec.gov.br/>.

4. BRASIL.CNE/CEB Ministério da educação, Secretária de Educação Básica. Resolução n 13.005 de 25 de Junho de 2014 define o Plano Nacional de Educação. Brasília. jun. de 2014. Disponível em $:<$ http://www.mec.gov.br/>.

5. COSTA, Marisa Vorraber. Sobre as contribuições das análises culturais para a formação dos professores do início do século XXI. Educar, n. 37, p. 129 - 152, maio/ago 2010.

6. COSTA, Marisa Vorraber. Sobre a escola e a cultura contemporânea. In: COSTA, Marisa Vorraber. A educação na cultura da mídia e do consumo. Rio de Janeiro: Lamparina, 2009, p. 60 - 75.

7. COSTA, Marisa Vorraber. Sujeitos e subjetividades nas tramas da linguagem e da cultura. In: $10^{\circ}$ ENDIPE - SIMPÓSIO SUJEITOS E SUBJETIVIDADES NA CONTEMPORANEIDADE, 2000, Rio de Janeiro. Anais. Rio de Janeiro: UFRJ, 2000p.

8. ENGUITA, Mariano Fernández. A ambiguidade da docência: entre o profissionalismo e a proletarização. Teoria \& Educação, n. 4, p. 41 - 61, 1991.

9. FABRIS, Elí Terezinha Henn. A pedagogia do herói nos filmes hollywoodianos. Currículo sem Fronteiras, n. 1, v. 10, p. 232-245, 2010.

10. FISCHER, Rosa Maria Bueno. Foucault e a análise do discurso em educação. Cadernos de Pesquisa, n. 114, p. 197 - 223, nov 2001.

11. FOUCAULT, Michel. A Arqueologia do Saber. $8^{\mathrm{a}}$ ed. Rio de Janeiro: Forense Universitária, 2015. $254 \mathrm{p}$.

A ordem do Discurso. 24. ed. São Paulo: Edições Loyola, 2014. 74 p.

13. GARCIA, Maria Manuela Alves; FONSECA, Márcia Souza da; LEITE, Vanessa Caldeira. Teoria e prática na formação de professores: a prática como tecnologia de eu docente. Educação em Revista, n. 3, v. 29, p. $233-264$, set. 2013.

14. GARCIA, Maria Manuela Alves; HYPOLITO, Álvaro Moreira; VIEIRA, Jarbas Santos. As identidades Docentes como Fabricação da Docência. Educação e Pesquisa, n.1, v. 31, p. 45 - 56, jan/abr. 2005. 
GARCIA, Maria Manuela Alves. Identidade docente. In: OLIVEIRA, Dalila Andrade; DUARTE, Adriana Maria Cancella; VIEIRA, Lívia Maria Fraga. Dicionário: trabalho, profissão e condição docente. Belo Horizonte: UFMG/Faculdade de Educação, 2010. CDROM. Reformas curriculares e formação inicial: saberes e profissionalização. Educação Unisinos, n. 1 , v. 19 , p. $57-67$, jan/abr. 2015

17. HALL, Stuart. A centralidade da cultura: notas sobre as revoluções culturais do nosso tempo. Educação \& Realidade, Porto Alegre, v. 22, n², p. 15-46, jul./dez. 1997.

18. LOPES, Claudivan Sanches; GASPARIN, João Luiz. Violência e conflitos na escola: desafios à prática docente. Acta Scientiarum. Human and Social Sciences, n. 2, v. 25, p. 294 - 304, 2003.

19. MARCELO, Carlos. Desenvolvimento profissional docente: passado e futuro. Sísifo. Revista de Ciências da Educação, n. 8, p. 7 - 22, jan/abr. 2009.

20. NÓVOA, Antônio. Os professores e a sua formação. 2 ed. Lisboa: Dom Quixote, 1995. 158p.

21. PEREIRA, Júlio Emílio Diniz. Formação de Professores: pesquisas, representações e poder. 2. ed. Belo Horizonte: Autêntica, 2006. 168p.

22. ROCHA, Simone Maria. Estudos culturais e estudos de mídia; modos de apresentação dos sujeitos em programas televisivos. Líbero, n. 21, ano XI, p. 87 - 98, jun. 2008.

23. ROCHA, Simone; MATOS, Daniela; SALVO, Fernanda; SOUTO, Mariana. Os estudos culturais e os entrelaçamentos entre comunicação e cultura: uma análise do filme Cão sem dono. Revista Interin, n.1, v. 9, p. 1-15, 2010.

24. ROCHA, Simone Maria. Os estudos culturais e a análise cultural da televisão: considerações teórico-metodológicas. Revista Interamericana de Comunicação Midiática, n. 19, v. 10, p. 1-20, 2011.

25. ROSA, Maria Inês Petrucci. Formação docente, identidade profissional e a disciplina escolar: práticas curriculares no ensino médio. ZETETIKÉ, Campinas, v. 18, 2010 p. 407-432. dos professores. 2015. 122F. Dissertação - Curso de Mestrado em Educação, Faculdade de Educação, Universidade Federal de São Carlos, Sorocaba. 


\section{Legenda de Imagens}

Fig. 1 - Notícia publicada na página Professores Sofredores (Fonte: Rede Social Facebook)

Fig. 2 - Notícia publicada na página Professores Sofredores (Fonte: Rede Social Facebook)

Fig. 3 - Notícia publicada na página Professores Sofredores (Fonte: Rede Social Facebook)

\section{Josiele Oliveira da Silva}

Graduada em Licenciatura em Química pela UFPel e doutoranda do Programa de Pós-graduação em Educação em Ciências: Química da Vida e Saúde pela UFRGS.

\section{Maira Ferreira}

Professora do Programa de Pós-graduação em Ensino de Ciências e Matemática da Universidade Federal de Pelotas e Professora Colaboradora do Programa de Pós-graduação em Educação em Ciências: Química da Vida e Saúde da Universidade Federal do Rio Grande do Sul.

\section{Como citar este documento:}

DA SILVA, Josiele Oliveira; FERREIRA, Maira. Representação de professores em redes sociais: discursos sobre a docência e identidade docente. Reflexão e Ação, Santa Cruz do Sul, v. 27, n. 1, dez. 2018. ISSN 1982-9949. Disponível em: <https://online.unisc.br/seer/index.php/reflex/article/view/9963>. Acesso em: . doi:https://doi.org/10.17058/rea.v27i1.9963. 